\title{
6-shogaol from ginger oleoresin loaded liposomes using DMPG-Na as a carrier enhances the in-vitro and in-vivo anticancer activity
}

\author{
Kiran Kemkar, Sathiyanarayanan L., Arulmozhi Sathiyanarayanan, Kakasaheb Mahadik \\ Bharati Vidyapeeth University, Poona College of Pharmacy, Pune-411 038, Maharashtra, India.
}

\begin{tabular}{l}
\hline ARTICLE INFO \\
\hline Article history: \\
Received on: 26/11/2017 \\
Accepted on: 08/01/2018 \\
Available online: 27/02/2018 \\
\\
\hline Key words: \\
6-Shogaol, Liposomes, Fac- \\
torial designs, Cytotoxicity, \\
Breast cancer.
\end{tabular}

\section{INTRODUCTION}

Now a day's natural dietary foods including vegetables, fruits, and spices aliments have been achieved a great attraction from the scientist of various health care departments, food industries and the normal public because of their safety, efficacy and availability at the comparatively lower price. In addition they are believed to have no or very less toxic effects than the synthetic drugs (Kelly et al., 2016; Shukla and Singh, 2007). However, the low aqueous solubility, poor bioavailability, and the stability of phytoconstituents lead to hamper their use in the treatment of various diseases. Therefore, various delivery system including nanotechnology-based drug-delivery systems have been designed for different naturally occurring phytoconstituents to increase the aqueous solubility, bio-availability and reduce the dose without hampering the efficacy of the drug, safety and the compatibility with patients (Bothiraja et al., 2013).

"Corresponding Author

Sathiyanarayanan L.; Associate Professor, Department of Pharmaceutical Chemistry, Bharati Vidyapeeth Deemed University, Poona College of Pharmacy, Pune-411 038, Maharashtra, India.

E-mail:pharmsathiya@gmail.com 6-shogaol rich ginger oleoresin (6-SRGO) is an oleoresin extracted from Zingiber officinale Rosc., containing higher content of phenolic ketones; gingerols and shogaols (Oriania et al., 2016; Singh et al., 2008). Traditionally 6-SRGO used for the treatment of cough, stomach upset, inflammation, diarrhea, nausea and vomiting. Among the various phenolic constituents of ginger oleoresin (GO), the analogs of shogaols and gingerols are known for their potent antioxidant, anti-inflammatory, and anticancer activities (Chen et al., 2012). Various studies have discovered that 6-shogaol (6-SGL) possesses most potent anti cancer activity than the other analogs of the shogaols and the gingerols (Wu et al., 2010). Various in vitro studies have demonstrated the role of 6-SGL in suppressing the different cancer cells like ovary (Kim et al., 2008), lungs, colon, gastrointestinal tract and neuroblastoma. The metabolites of 6-SGL are also known to possesses anticancer activity (Shukla and Singh, 2007; Surh et al., 1998).

The major challenge of using 6-SGL is its poor aqueous solubility; which limits its therapeutic efficacy (Nikam et al., 2013). High dose of 6-SRGO is required to reach the therapeutic efficacy, which may lead to the several side effects such as diarrhea, nausea and many times the tolerance of the 
6-SRGO. There are few attempts have been made to develop nanoformulations using conventional extract of ginger but detail investigation, characterization and anticancer potential are not reported (Kumar et al., 2011; Uthumpa et al., 2013; Ratcharin et al., 2012). Prompted by the above facts, present research aims at incorporating 6-SRGO within polymers to develop a drug delivery system displaying enhanced drug solubility, achieving site-specific tumor accumulation while reducing systemic toxicity of 6-SRGO.

Nanoparticular drug delivery systems using liposomes is an emerging technologies for the rational delivery of cytotoxic drugs in the treatment of cancer (Gao et al., 2011; Li et al., 2011; Tong et al., 2012; Muthu et al., 2012; Saxena and Hussain, 2012). Their use offers solubilization of water insoluble drugs, high drug loading, improved stability, increases circulation time, improved tissue targeting, control and extended drug release and lower systemic toxicity (Malam et al., 2009). Liposomes are closed spherical vesicles consisting of a lipid bilayer that encapsulates poorly water soluble drugs into the inner hydrophobic core thus improving solubility, stability and bioavailability (Akbarzadeh et al., 2013). Due to its outer hydrophobic shell and nano size particles they sometimes evince prolonged circulation times in vivo and can hoard in tumoral tissues. The liposomes size varies from 200-400 $\mathrm{nm}$ adduce rival physical and chemical properties that can be exploited for drug delivery by conjugation with drugs. The commercial availability of liposomal Doxil and albuminnanoparticle-based Abraxane has existed for the treatment of the cancer. Due to above applications, liposomes offer increased precision in chemotherapeutic targeting of breast cancer.

To the best of our knowledge no previous studies have attempted the preparation of 6-SRGO-loaded liposomes (LLPS) to improve its anticancer efficacy. Therefore, this study was attempted to investigate the potentials of 6-shogaol rich ginger oleoresinloaded liposomes (6-SRGO-LLPS), which may enhance solubility, physiological stability and anticancer efficiency of 6-SRGO.

\section{MATERIALS \& METHODS}

\section{Carrier and core materials}

Liposomeswereproducedusing a carrier 1,2-Dimyristoylsn-glycero-3-phospho-rac-glycerol, sodium salt, (DMPG-Na)lipid that was supplied by Lipoid, Cologne, Germany, with melting point at $122^{\circ} \mathrm{C}$. The reference standard (pure isolated) 6-shogaol (>96\% purity w/w) was procured from Natural Remedies Pvt. Ltd. Bangalore, Karnataka, India. 6-SRGO was purchased from Nisarg Biotech, Satara, Maharashtra, India. Dialysis bags (MW cut-off 12,000) were purchased from Sigma-Aldrich Chemical Private Ltd (Bangalore, India). All other reagents and chemicals used in this study were of analytical grade and procured from Merck Specialties Private Limited, Mumbai, India.

\section{Quantification of 6-SGL present in GO}

6-shogaol present in ginger oleoresin was quantified using RP-HPLC method which was reported in our earlier study (Nikam et al., 2013).

\section{Preparation of 6-SRGO-LLPS}

6-SRGO-LLPS were prepared according to solvent injection technique (Laouini et al., 2012). Extraction of 6-SGL was performed by adding the ginger oleoresin to a chloroform containing a specific amount of DMPG-Na followed by mixing with a suitable quantity of cholesterol under stirring at room temperature. To the sufficient distilled water, above mixture was added rapidly under magnetic stirring at $2000 \mathrm{rpm}$ for $45 \mathrm{~min}$ followed by sonication for 10 min to obtain liposome suspension. Blank liposomes (devoid of 6-SRGO) were prepared in the similar manner.

\section{Optimization of 6-SRGO-LLPS by $3^{2}$ factorial designs}

$3^{2}$ factorial designs was adopted to optimize the liposomes composition while studying the effect of lipid and cholesterol (independent variables) on Drug Content (DC), Entrapment Efficiency (EE) and Particle Size (PS) (three dependent variables or responses) by obtaining a response surface plot.

\section{Characterization of 6-SRGO-loaded liposomes}

\section{Liposomes size distribution \& zeta potential}

The size of blank and 6-SRGO-LLPS was determined by laser diffraction technique (Malvern 2000 SM; Malvern Instruments, Malvern, UK). The particle size measurements were carried out at a $90^{\circ}$ scattering angle. The samples were dispersed in distilled water and the average PS was determined and expressed in terms of $d(0.9) \mu \mathrm{m}$. The zeta potential was measured with the laser doppler electrophoretic mobility measurements using Zetasizer 3000 (Malvern Instruments) at a temperature of $25^{\circ} \mathrm{C}$.

$D C \& E E$

The concentration of 6-SGL in the liposomes was determined by rapid and sensitive RP-HPLC method. The superficial 6-SGL was determined by washing 6-SRGO-LLPS with ethanol and measuring the 6-SGL content collected in the washing solution. EE was determined as the ratio between the encapsulated 6-SGL (total - superficial) and the feeding amount of 6-SGL (active compound). The DC was determined as the ratio between the mass of liposomes collected at the end of the process and the mass of carrier added to 6-SRGO used in the production of liposomes.

\section{Physical characterization}

\section{Fourier transform infrared spectroscopy}

The pure 6-SRGO, DMPG-Na and 6-SRGO-LLPS were characterized by FTIR spectroscopy in the 4000 to $400 \mathrm{~cm}^{-1}$ region using FTIR Spectrophotometer (Jasco 4100).

\section{Differential scanning calorimetry}

Thermal analyses were performed by differential scanning calorimetry (DSC 821, Mettler Toledo). Approximately $5 \mathrm{mg}$ of 6-SRGO-LLPS were heated in hermetically sealed alluminium pan with heating rate $10^{\circ} \mathrm{C}$ per min under nitrogen atmosphere (flow rate $50 \mathrm{ml} / \mathrm{min}$ ). The pure 6-SRGO was also analyzed for comparison.

\section{Surface morphology}

The morphology of 6-SRGO-LLPS was performed using transmission electron microscopy (TEM). The sample preparation for the TEM was followed by (Bothiraja et al., 2013). 


\section{Evaluation of 6-SRGO-LLPS stability}

6-SRGO-LLPS were transferred in glass vials with plastic lids, protected from the light, and stored at $25^{\circ} \mathrm{C}$ for 90 days for short term stability studies. Liposomes were evaluated with regard to the content of 6-SGL, PS and EE.

\section{In vitro release of 6-SRGO from liposomes}

The in vitro release of 6-SRGO-LLPS was carried out in $0.1 \mathrm{~N} \mathrm{HCL}(\mathrm{pH}$ 1.2) and in phosphate-buffer ( $\mathrm{pH}$ 7.4) using dialysis bag diffusion technique. A formulation equivalent to 1 $\mathrm{mg}$ of 6-SRGO or $1 \mathrm{mg} 6-\mathrm{SRGO}$ solution $(1 \mathrm{mg} / \mathrm{ml}$ in $50 \% \mathrm{w} / \mathrm{w}$ mixture of PEG 400 and water) as control was introduced into a dialysis bag (cellulose membrane, MW cut-off 12,000 Da), sealed and immersed into $50 \mathrm{ml}$ of release medium. The temperature of entire system was maintained at $37 \pm 0.5^{\circ} \mathrm{C}$ with continuous magnetic stirring at $100 \mathrm{rpm}$. At previously planned time intervals, the sample was removed and replaced with an equal volume of fresh medium in order to maintain sink conditions. 6-SGL present in the solution was quantified by using rapid and sensitive RP-HPLC method. Analysis of data was performed using PCP Disso software (V3; Poona College of Pharmacy, Pune, India).

\section{In vitro cytotoxicity study}

In vitro cytotoxicity study of free 6-SRGO, blank liposomes and 6-SRGO-LLPS were evaluated against human breast cancer MCF-7 using in vitro SRB assay at Advanced Centre for Treatment, Research and Education in Cancer (ACTREC), Mumbai. The results of MCF-7 were compared with that of marketed Adriamycin (Doxorubicin). The cytotoxicity protocol for SRB assay was followed by method described by (Kaushik et al., 2015).

\section{Acute toxicity study}

The acute toxicity study was performed for 6-SRGO and 6-SRGO-LLPS on swiss albino mice. The animals were randomly divided into eleven groups $(n=6)$. The first group (control group) received feed and distilled water orally. Groups 2-6 were orally treated with 6-SRGO with doses $55 \mathrm{mg} / \mathrm{kg}, 175 \mathrm{mg} / \mathrm{kg}, 550 \mathrm{mg} / \mathrm{kg}$, $1750 \mathrm{mg} / \mathrm{kg}$ and $2000 \mathrm{mg} / \mathrm{kg}$ body weight, respectively. Groups 7-11 were orally treated with 6-SRGO-LLPS with doses $55 \mathrm{mg} /$ $\mathrm{kg}, 175 \mathrm{mg} / \mathrm{kg}, 550 \mathrm{mg} / \mathrm{kg}, 1750 \mathrm{mg} / \mathrm{kg}$ and $2000 \mathrm{mg} / \mathrm{kg}$ body weight, respectively. The animals were continuously observed for general behavioral changes, sign of toxicity, and mortality for $1 \mathrm{~h}$ after treatment and then intermittently for $4 \mathrm{~h}$ and thereafter over a period of $24 \mathrm{~h}$. Mice were further observed for up to 14 days for behavioral change and sign of toxicity.

\section{In vivo anti cancer activity of 6-SRGO and 6-SRGO-LLPS against Dalton's Ascitic Lymphoma (DAL) in mice}

\section{Selection grouping and acclimatization of laboratory animal}

Male Swiss albino mice having the weight range of 20 gm to $25 \mathrm{gm}$ were used to conduct this study. They were kept in to micro nylon boxes at control temperature (temp $25 \pm 2{ }^{\circ} \mathrm{C}$ ).

"The protocol of the study was approved by Institutional Animal Ethics Committee (IAEC) constituted in accordance with the rules and guidelines of the Committee for the Purpose of Control and Supervision on Experimental Animals (CPCSEA),
India (approval number CPCSEA/Q.A./01/2014-15; institutional approval no- CPCSEA/1999/100). The Declaration of Helsinki as amended in Seoul 2008 for humans, and the European Community guidelines as accepted principles for the use of experimental animals, was followed."

\section{Induction of cancer cells}

DLA cells were procured from Amala cancer research center, Trissur, Kerala, India. The cancer cells implants in vivo in mice by intraperitoneal route. Before transferring the cancerous cells to mice, by using saline solution the DLA cells were taken from peritoneal cavity of the mice. The total cells count was maintained up to $1 \times 10^{6}$ after dilution and was given intraperitoneally. The treatment was started after seven days of induction of tumor cells (Sathiyanarayanan et al., 2006; Unnikrishnan and Kuttan, 1990).

\section{Grouping of the mice and outline of the treatment}

Animals were grouped in to nine groups with each group contains six animals. The animals of eight groups have given DLA cells $\left(1 \times 10^{6}\right.$ cells per mice $)$ intraperitoneally, and one group is remains as a control group.

Group 1 and 2 represents normal control and tumor control respectively.

Group 3 represents positive control, (Received 5-fluoro uracil injection at $20 \mathrm{mg} / \mathrm{kg}$ body weight)

Group 4, 5, and 6 represents treatment control, (Received 6-SRGO at a dose of $100 \mathrm{mg} / \mathrm{kg}, 200 \mathrm{mg} / \mathrm{kg}$ and 400 $\mathrm{mg} / \mathrm{kg}$ body weight respectively through orally).

Group 7, 8, and 9 represents treatment control group, (Received 6-SRGO-LLPS at a doses of $100 \mathrm{mg} / \mathrm{kg}, 200 \mathrm{mg} / \mathrm{kg}$ and $400 \mathrm{mg} / \mathrm{kg}$ body weight respectively through orally).

\section{Evaluation of clinical parameters}

During this study, the cancer cells were inoculated in to the animals and the treatment for cancer was started after $24 \mathrm{hrs}$ once a day for 14 days. Once after all the doses were finished, animals were sacrificed by euthanasia. The samples of the blood were withdrawn from each mouse at predetermined time from retro orbital plexus bleeding. Various parameters were checked which include, count of the cancer cells, hematological parameters consist of content of $\mathrm{Hb}, \mathrm{RBC}$ count, WBC count, platelet count and the volume of packed cells, serum enzyme and lipid profile including count of total cholesterol (TC), triglycerides (TG), aspartate amino transferase (AST), alanine amino transferase (ALT) and alkaline phosphatase (ALP) and the derived parameters such as total life span (\%) of the animal, body weight of the animal used and the cancer cell count.

\section{Statistical analysis}

All data are expressed as means \pm SEM. One way ANOVA followed by Dunnettspost test was used for in vivo anticancer activity. $\mathrm{P}<0.01$ was considered as significant. Prism 5 Demo software has been used for the statistical analysis.

\section{RESULTS AND DISCUSSION}

6-SGL is well known for its anticancer potential. However its usage is limited due to its low solubility, low stability 
in GI and low bioavailability. GO consists of higher amount of shogaols and gingerols compare to normal solvent extracts. Hence usage of GO is ideal for anticancer purposes especially due to the presence of higher amount of 6-SGL. Further, synergistic effect of herbals is always plays a role in therapeutic applications. Although the pharmacological activities are attributed to active constituents, practically isolation and formulation of pure compounds from herbals are expensive processes and there are possibilities of reduction in therapeutic activity due to lack of synergism while using single compound. So it is worthwhile to develop drug delivery systems for multi chemical compositions from herbals rather than single compound. Considering these facts in present study, 6-SRGO-LLPS have been developed and investigated as nanocarriers for oral administration in order to enhance both in vitro and in vivo anticancer activity of 6-SGL in GO.

\section{Quantification of 6-SGL present in ginger oleoresin}

In the present study 6-SGL present in the GO was quantified by rapid and sensitive RP-HPLC method and the 6-SGL was quantified at retention time of $10.30 \mathrm{~min}$ at the wavelength $281 \mathrm{~nm}$ (Figure 1). The amount of 6-SGL present in 6-SRGO was found to be $20 \% \pm 2 \%$ where as the optimized formulation 6 -SRGO-LLPS was found to have $16 \% \pm 1 \%$. The reduction in the amount of 6-SGL in the optimized formulation is due to the drug loss during the preparation of liposomes.

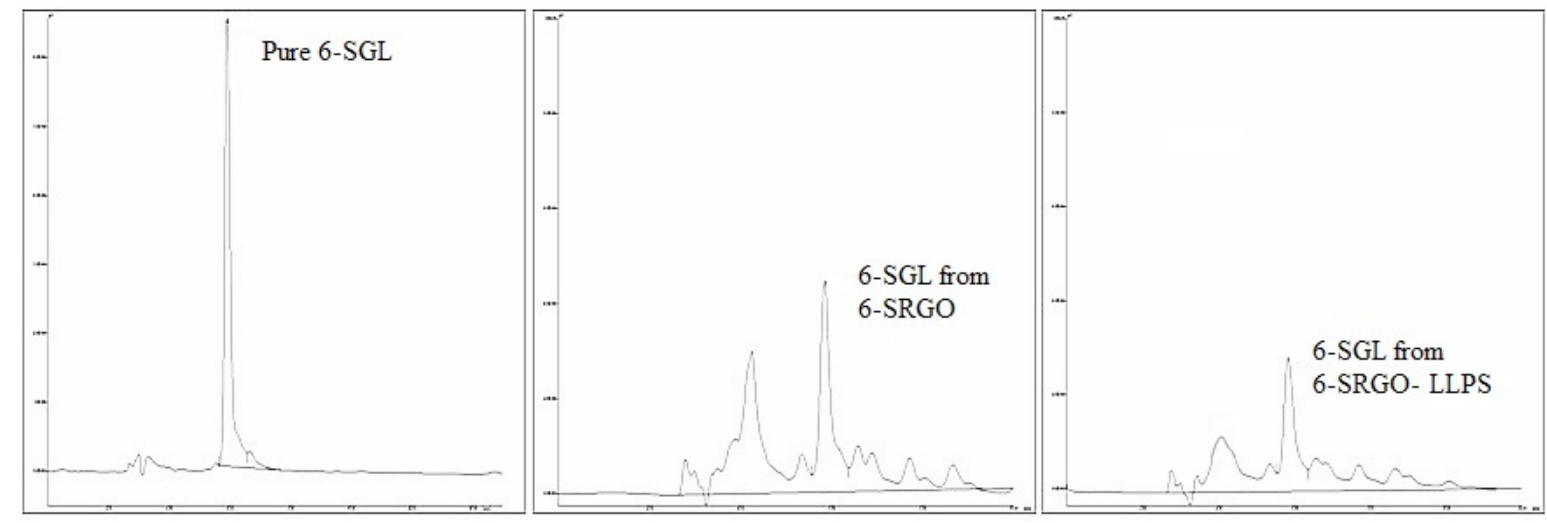

Fig. 1: HPLC chromatograms of pure 6-SGL (A), 6-SGL from 6SRGO (B) and 6-SGL from 6-SRGO-LLPS (C) formulation.

\section{Preparation and optimization of 6-SRGO-LLPS by $3^{2}$ factorial designs}

6-SRGO-LLPS was prepared and the effect of these liposomes composition on DC, EE and PS was studied by $3^{2}$ factorial designs (Shukla and Singh, 2007). The mean PS was observed in between $250-450 \mathrm{~nm}$ and was affected by the selected variables $\left(\mathrm{r}^{2}=0.9247\right)$. The $\mathrm{DC}$ and $\mathrm{EE}$ were in the range of $79-96 \%$ and $72-88 \%$ respectively. A good fit $\left(r^{2}\right.$ for $\mathrm{DC}=0.8580$ and $\mathrm{EE}=0.9236$ ) was observed between the $\mathrm{DC}, \mathrm{EE}$ and the independent variables.

A series of 6-SRGO-LLPS were prepared and observed physically for phase separation. In process of preformulation study, the concentration of DMPG-Na and cholesterol that would give non-coagulation and non-sedimenting liposomes were determined. A $3^{2}$ factorial design was taken to optimize their concentrations. The concentration of 6-SRGO was kept constant. As per $3^{2}$ factorial designs, nine different batches of different concentration ratio of lipid and cholesterol were prepared. The responses obtained from these batches are shown in Table 1. The data obtained was subjected to multiple regression analysis using Design Expert 10 software.

The results of multiple regression analysis of the obtained data are summarized in Table 1. The adequacy of fitted model was checked by analysis of variance. To study the interaction effects of the independent variables, response surface plots were constructed using Design Expert 10 software (Figure 2).

From the factorial design study (Table 1), it is observed that positive coefficients of the main term X1 and the interaction term X1X1 indicated a favorable effect on the mean liposomes size, with the lipid chiefly influencing than cholesterol. The lipid had a linear effect on the mean liposomes size as seen in surface plot (Figure 2A). Smaller liposomes were obtained at low lipid content, probably due to high distribution efficiency of internal phase into external phase. Increase in the viscosity of internal phase with increased amount of lipid also provides resistance for mass transfer during diffusion of internal phase into the external phase leading to liposomes enlargement. The increase in the mean liposomes size may also be due to hydrophobic-hydrophobic interaction of lipid with the drug.

Table 1: Regression analysis results of measured responses.

\begin{tabular}{lccc}
\hline \multirow{2}{*}{ Coefficients } & \multicolumn{3}{c}{ Parameters } \\
\cline { 2 - 4 } & Particle size & Drug content & $\begin{array}{c}\text { Encapsulation } \\
\text { efficiency }\end{array}$ \\
\hline$\beta 0$ & 356.11 & 89.92 & 79.36 \\
$\beta 1$ & 50.33 & +1.79 & +5.21 \\
$\beta 2$ & 12.67 & +1.58 & +5.58 \\
$\beta 11$ & - & -0.62 & -1.42 \\
$\beta 22$ & - & -0.50 & -1.17 \\
$\beta 12$ & - & +0.12 & -0.38 \\
$\mathrm{r}^{2}$ & 0.9247 & 0.8580 & 0.9236 \\
\hline
\end{tabular}

Both X1 and X2 showed favorable positive effects on DC and EE. In case of lipid it showed linear effect on DC and EE. Further more in case of cholesterol, it also showed linear effects on DC and EE. As seen in surface plot (Figure 2B \& 2C), the lipid favored DC and EE by hydrophobic-hydrophobic interactions 
with drugs leading to formation of interpenetrated network chain. However, cholesterol exerted an opposite effect as it led to solubilization of the drug in the external phase.

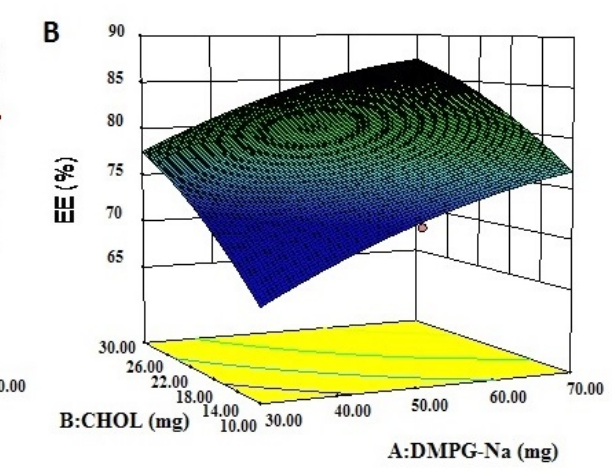

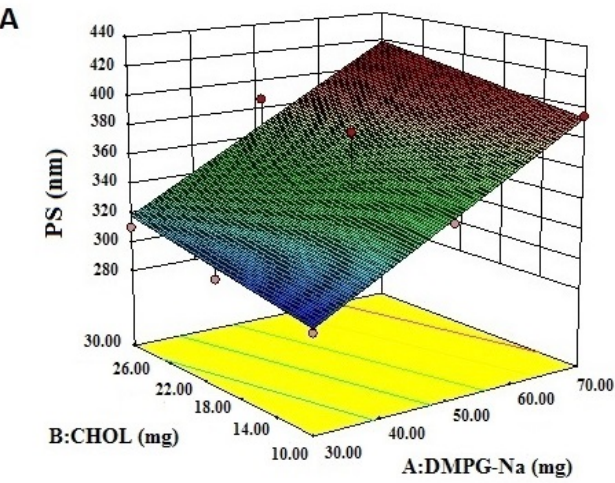

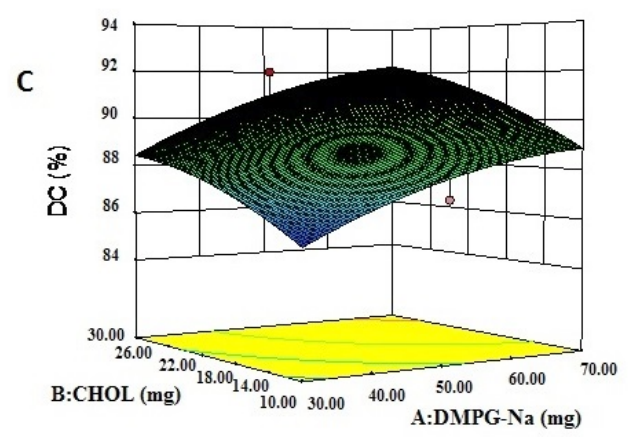

Fig. 2: Response surface plot illustrating effect of factorial variables. (A) Particle size, (B) Encapsulation Efficiency, (C) Drug Content.

Based on the results of the factorial designs, 6-SRGOLLPS having acceptable PS, DC and EE was selected as an optimized batch. The size of the optimized 6-SRGO-LLPS was $380 \pm 3 \mathrm{~nm}$ - which was not significantly different from its blank counter part. Large molecules of more than $40 \mathrm{kDa}$ in size and certain particles ranging from 10 to $400 \mathrm{~nm}$ can leave the vascular bed and accumulate inside the interstitial space of the tumor (EPR effect) (Gao et al., 2011). Drug delivery to specific sites of the body is influenced by size of the liposomes; smaller liposomes may tend to minimize the particle uptake by non targeted cells, including their premature clearance by the mononuclear phagocytic system (Brigger et al., 2002). It is hypothesized that liposomes developed in the present study are of appropriate size to be able to passively target the tumor site.

\section{Physical characterization}

\section{Fourier transform infrared spectroscopy}

6-SRGO, DMPG-Na, and 6-SRGO-LLPS were analyzed by Fourier transform infrared (FTIR) spectroscopy and the results are showed in (Figure 3).

In the IR spectra (Figure 3A) of 6-SRGO following peaks were assigned, -OH stretching $\left(\sim 3124 \mathrm{~cm}^{-1}\right)$, Aromatic $\mathrm{CH}$ stretching ( 2994 $\left.\mathrm{cm}^{-1}\right)$, Aliphatic $-\mathrm{CH}$ stretching ( 2852 $\left.\mathrm{cm}^{-1}\right),-\mathrm{C}=\mathrm{O}$ stretching $\left(\sim 1736 \mathrm{~cm}^{-1}\right)$ and $\mathrm{OH}$ bending out of plan $\left(\sim 1373 \mathrm{~cm}^{-1}\right)$, while in the formulation (Figure 3C), 6-SRGO incorporated with polymer lipid, remarkable peaks of active drug such as $-\mathrm{OH}$ stretching at $\left(\sim 3124 \mathrm{~cm}^{-1}\right)$ were not observed. Thus final IR spectra of 6-SRGO-LLPS revealed that 6-SRGO has been completely encapsulated with lipid in the formulation.

\section{Differential scanning calorimetry}

Differential scanning calorimetry was performed with 6-SRGO-LLPS to determine the onset, maximum temperature and enthalpy of 6-SRGO-LLPS and 6-SRGO (Figure 4). According to the results, melting point of free 6-SRGO was observed at around $240^{\circ} \mathrm{C}$ with the enthalpy $31.11 \mathrm{~J} / \mathrm{g}$. In case of 6-SRGO-LLPS thermogram, the free 6-SRGO peak was disappeared and shifted to $169^{\circ} \mathrm{C}$ indicating molecular dispersion of 6-SRGO inside liposomes. Thermograms of 6-SRGO-LLPS exhibited a sharp endothermic peak starting at approximately $145^{\circ} \mathrm{C}$ and ending at approximately $185^{\circ} \mathrm{C}$. Onset temperature at approximately $145^{\circ} \mathrm{C}$ and melting point around $169^{\circ} \mathrm{C}$ are desirable for particle stability at room or lower temperatures and digestibility in the gastrointestinal tract, respectively, acting as a trigger to release the active core during the digestion process (Tulini et al., 2016).

\section{Surface morphology}

The obtained 6-SRGO-LLPS solution appeared clear and light yellowish in color. Figure also revealed that the prepared formulation was monodispersed in water phase, tightly packed and spherical shaped liposomes whose size measured by laser scattering technique was correlated well with that by TEM (Figure $5)$. 




Fig. 3: Fourier transform infrared (FT/IR) spectroscopy analyses of (C) 6-SRGO-LLPS, compared with (A) 6-SRGO and (B) Phospholipid.

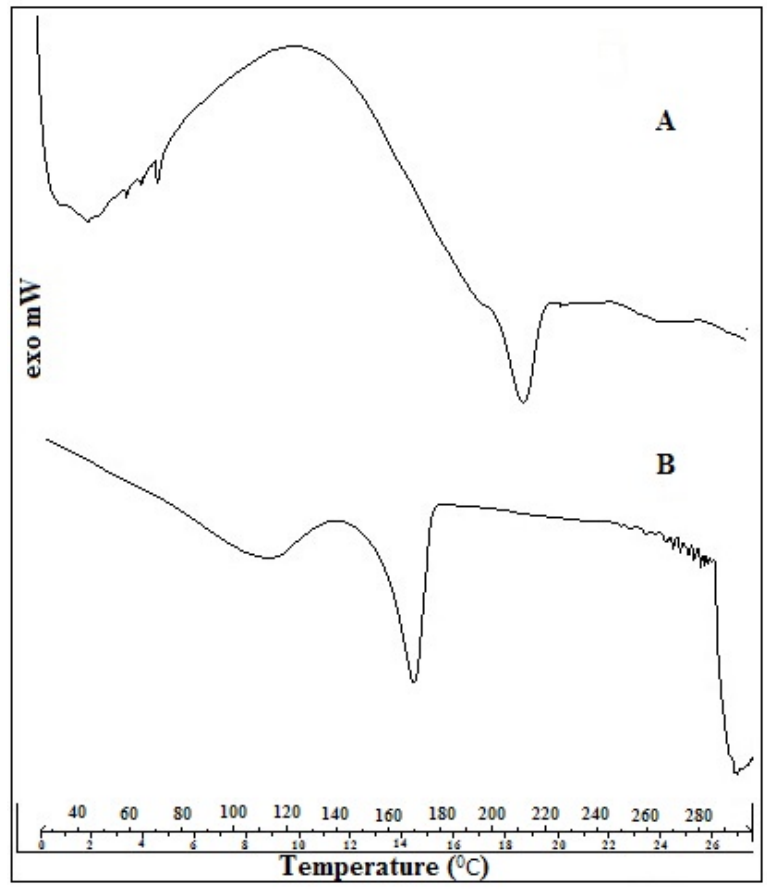

Fig. 4: Differential scanning calorimetry (DSC) analyses of (A) 6-SRGO and (B) 6-SRGO-LLPS. 


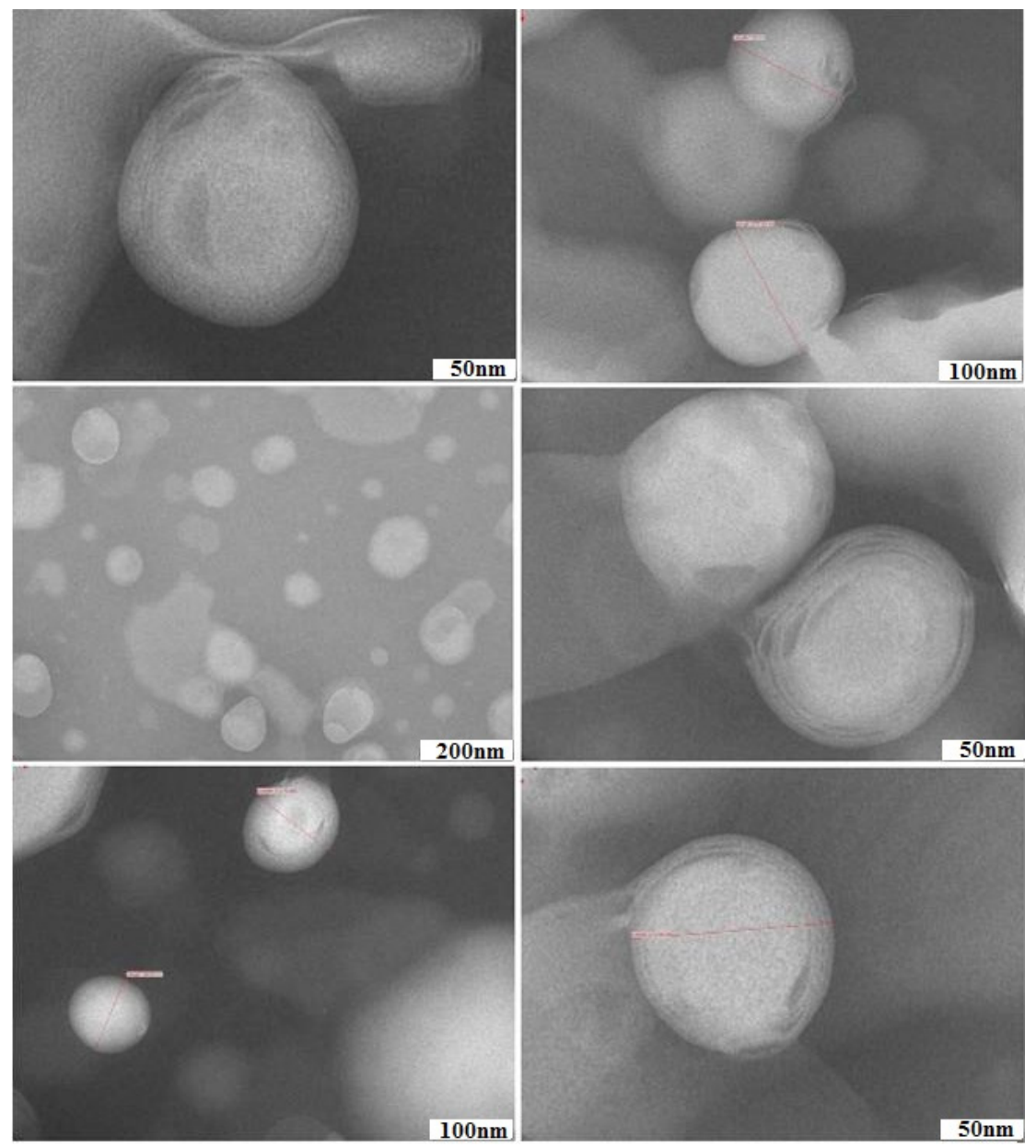

Fig. 5: Transmission electron micrograph of optimized 6-SRGO-LLPS.

The TEM image showed that there is no drug crystallization appears in the 6-SRGO-LLPS and the surface of the liposomes are smooth and they are suspended uniformly in the formulation.

\section{Evaluation of 6-SRGO-LLPS stability}

Stability study reveals that 6-SRGO-LLPS did not show noticeable changes in their size $(340 \pm 15 \mathrm{~nm})$ and EE $(79 \pm 2.01 \%)$. The sedimentation of the drug was not observed during short-term stability studies. A drug loss of meager $3.62 \%$ was probably due to the partial decomposition of 6-SGL. These indicated that the drug-loaded liposomes were physically stable at room temperature for at least 3 months.

\section{In vitro release study}

The dialysis method is the most suitable method that simulated the circumstance of drug in vivo. The release pattern of 6-SRGO-LLPS in comparison with 6-SGL from 6-SRGO was investigated in gastric fluids ( $\mathrm{pH}$ 1.2) and intestinal fluids ( $\mathrm{pH} 7.4)$. Figure 6 showed the dissolution profile of 6-SGL from 6-SRGOLLPS and 6-SRGO in both $\mathrm{HCl}(\mathrm{pH} 1.2)$ and phosphate buffer saline ( $\mathrm{pH} 7.4)$, respectively. 6-SGL release from liposomes was always slower than the corresponding 6-SGL from 6-SRGO which escaped rapidly from the dialysis bag approximately $60 \%$ within 2 $\mathrm{h}$ and the release was over $95 \%$ by $6 \mathrm{~h}$. The profile of the $6-\mathrm{SRGO}-$ LLPS showed a very slow release of 6-SGL approximately $30 \%$ within $2 \mathrm{~h}$ and the release was over $90 \%$ by $42 \mathrm{~h}$.

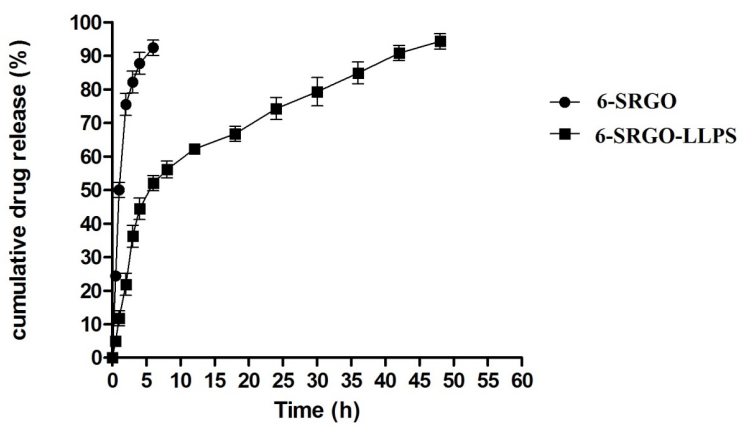

Fig. 6: In vitro release profiles of 6-SGL from 6-SRGO and from 6-SRGO-LLPS.

The drug release rate between liposomes at both $\mathrm{pH}$ ranges was tested. The 6-SGL from 6-SRGO exhibited faster release than the 6-SRGL-LLPS at all the $\mathrm{pH}$ ranges evaluated. The 6-SGL release behavior reflected the 6-SGL incorporation stability in the liposomes. The drug incorporated into the inner core compartment stayed tightly inside the liposomes. The results suggested that $\mathrm{pH}$ had little effect on the dissolution of 6-SGL from the liposomes, while 6-SGL release markedly increased with increasing $\mathrm{pH}$ value. The reason may be that as an, 6-SGL is 
unstable in low $\mathrm{pH}$ i.e. in gastric condition, which may lead to a

low bioavailability of 6-SGL from 6-SRGO.

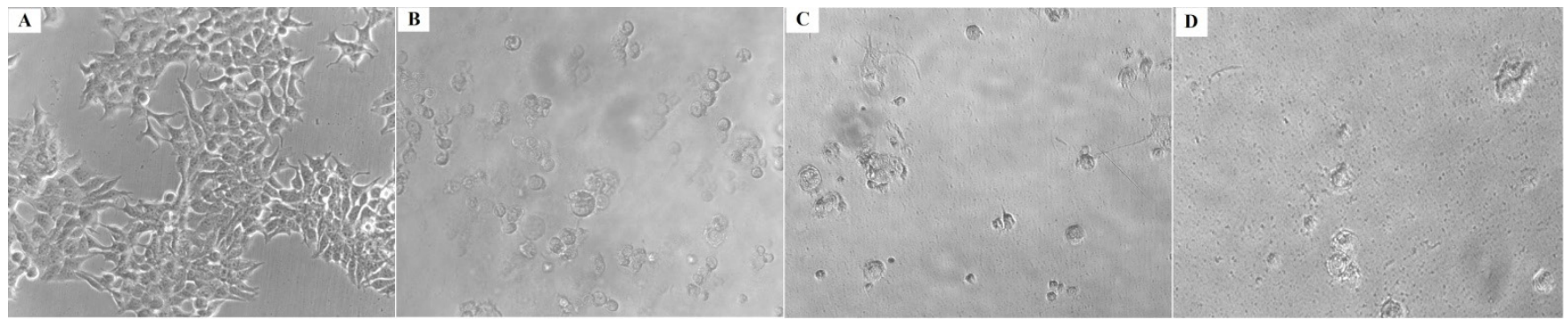

Fig. 7: In vitro cytotoxicity study on breast cancer cell line (MCF 7), (A) MCF 7 control, (B) Treatment control, (C) Treated with 6-SRGO, (D) Treated with 6-SRGO-LLPS.

Table 2: In vitro anticancer effect of 6-SRGO-LLPS on breast cancer cell MCF-7.

\begin{tabular}{lccc}
\hline & \multicolumn{2}{c}{ Drug concentration $(\boldsymbol{\mu g} / \mathbf{m l})$ calculated from graph } \\
\hline \multicolumn{1}{c}{ MCF 7 } & LC50 & TGI & GI50 \\
\hline 6-SRGO & $>80$ & 56.4 & 26.8 \\
Blank & $>80$ & $>80$ & $>80$ \\
6-SRGO-LLPS & $>80$ & 38.4 & $<10$ \\
ADR & 60.8 & 29.5 & $<10$ \\
\hline
\end{tabular}

Each point represents an average $\pm \operatorname{SD}(n=3)$.

\section{In vitro cytotoxic activity}

The in vitro cytotoxic activity of 6SRGO-LLPS was investigated and compared with free drug in solution, blank liposomes and marketed Adriamycin (Doxorubicin) against human breast cancer MCF-7 cells using in vitro SRB assay. The LC50, TGI and GI50 values were illustrated in Table 2, indicated that 6SRGOLLPS displayed better cytotoxic activity than the 6-SRGO and the blank liposomes. The GI50 concentration against MCF-7 was found to be $<10 \mu \mathrm{g} / \mathrm{ml}, 26.8 \mu \mathrm{g} / \mathrm{ml}$ and $>80 \mu \mathrm{g} / \mathrm{ml}$ for 6-SRGO-LLPS, 6-SRGO and blank liposomes respectively (Fig. 7).

Table 3: Effect of 6-SRGO and 6-SRGO-LLPS on Hematological parameters.

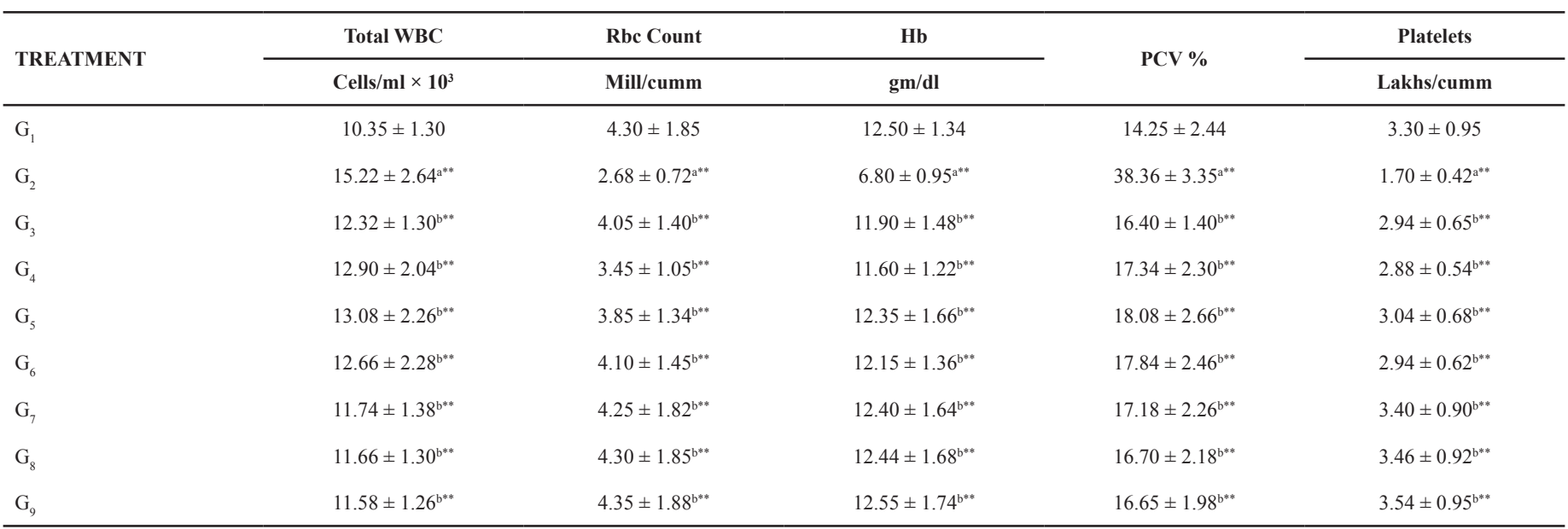

$\mathrm{G}_{1}$ - Normal Control, $\mathrm{G}_{2}$ - Cancer Control, $\mathrm{G}_{3}$ - Positive control, $\mathrm{G}_{4}$ to $\mathrm{G}_{6}$ - Treatment control (6-SRGO 100, 200, $\left.400 \mathrm{mg} / \mathrm{kg}\right), \mathrm{G}_{7}$ to $\mathrm{G}_{9}-$ Treatment control (6-SRGO-LLPS $100,200,400 \mathrm{mg} / \mathrm{kg}$ ).

All values are expressed as mean \pm SEM for 6 animals in each group and results were analyzed by using One way ANNOVA, followed by Dunnettspost test

${ }^{* * *}$ Values are significantly different from normal control $\left(\mathrm{G}_{1}\right)$ at $\mathrm{P}<0.01$

${ }^{* * b}$ Values are significantly different from cancer control $\left(\mathrm{G}_{2}\right)$ at $\mathrm{P}<0.01$.

The enhanced cytotoxic activity of 6-SRGO-LLPS may be attributed to greater cellular uptake of liposomes via phagocytosis or the fusion process of lipid liposomes. Therefore, 6-SRGO-LLPS might have served as a potential nanocarrier to improve the in vitro cytotoxic activity of 6-SGL. The lower cytotoxic activity of free drug in solution, blank liposomes may be due to its efflux by P-glycoprotein pumps.

\section{Acute toxicity study}

No death or toxic effect on tested animals were recorded during first $24 \mathrm{~h}$ as well as 14 days of observation after oral treatment of 6-SRGO and 6-SRGO-LLPS at the doses of $55 \mathrm{mg} / \mathrm{kg}, 175 \mathrm{mg} /$ $\mathrm{kg}, 550 \mathrm{mg} / \mathrm{kg}, 1750 \mathrm{mg} / \mathrm{kg}$ and $2000 \mathrm{mg} / \mathrm{kg}$ body weight.

The present study showed that oral administration of 6-SRGO and 6-SRGO-LLPS in acute dose up to $2000 \mathrm{mg} / \mathrm{kg}$ body weight did not produce any sign of toxicity or death in mice, suggesting a lethal dose 50\% (LD50) above $2000 \mathrm{mg} / \mathrm{kg}$. An acute toxic study provides a guideline for selecting doses for in vivo study (1/10th and $1 / 20$ th of maximum dose in mice) which may be more clinically relevant (Mehta et al., 2009). Thus, derived doses of $100 \mathrm{mg} / \mathrm{kg}, 200 \mathrm{mg} / \mathrm{kg}$ and $400 \mathrm{mg} / \mathrm{kg}$ for both 6-SRGO and 6-SRGO-LLPS have been selected. 
Table 4: Effect of 6-SRGO and 6-SRGO-LLPS on serum Enzymes and lipid proteins.

\begin{tabular}{|c|c|c|c|c|c|}
\hline \multirow{2}{*}{ Treatment } & Cholesterol & TGL & AST & ALT & ALP \\
\hline & (mg/dl) & (mg/dl) & $(\mathrm{U} / \mathrm{L})$ & $(\mathbf{U} / \mathbf{L})$ & $(\mathbf{U} / \mathbf{L})$ \\
\hline $\mathrm{G}_{1}$ & $110.085 \pm 3.05$ & $136.85 \pm 2.55$ & $38.40 \pm 1.65$ & $33.28 \pm 1.45$ & $132.28 \pm 2.40$ \\
\hline $\mathrm{G}_{2}$ & $146.95 \pm 4.34^{\mathrm{a}^{* * *}}$ & $220.28 \pm 4.40^{\mathrm{a}^{* * *}}$ & $78.6 \pm 2.74^{\mathrm{a}^{* *}}$ & $62.32 \pm 2.60^{0^{* * *}}$ & $265.30 \pm 4.35^{\mathrm{a}^{* *}}$ \\
\hline $\mathrm{G}_{3}$ & $126.30 \pm 3.84^{\mathrm{b}^{* *}}$ & $169.15 \pm 2.65^{\mathrm{b}^{* *}}$ & $44.40 \pm 1.72^{\mathrm{b}^{* *}}$ & $34.52 \pm 1.70^{b^{* *}}$ & $154.45 \pm 2.40^{\mathrm{b}^{* * *}}$ \\
\hline $\mathrm{G}_{4}$ & $123.44 \pm 3.64^{\mathrm{b}^{* *}}$ & $172.32 \pm 2.84^{\mathrm{b}^{* *}}$ & $50.15 \pm 2.82^{\mathrm{b}^{* *}}$ & $40.35 \pm 2.02^{\mathrm{b}^{* *}}$ & $171.85 \pm 2.90^{\mathrm{b}^{* * *}}$ \\
\hline $\mathrm{G}_{5}$ & $122.30 \pm 3.60^{\mathrm{b}^{* * *}}$ & $166.15 \pm 2.56^{\mathrm{b}^{* *}}$ & $49.05 \pm 2.32^{\mathrm{b}^{* *}}$ & $36.84 \pm 1.86^{b^{* * *}}$ & $172.35 \pm 2.94^{\mathrm{b}^{* *}}$ \\
\hline $\mathrm{G}_{6}$ & $114.20 \pm 3.52^{\mathrm{b}^{* *}}$ & $171.80 \pm 2.76^{\mathrm{b}^{* *}}$ & $46.50 \pm 2.20^{\mathrm{b} * *}$ & $37.35 \pm 1.94^{b^{* * *}}$ & $167.34 \pm 2.36^{\mathrm{b} * *}$ \\
\hline $\mathrm{G}_{7}$ & $112.45 \pm 3.26^{\mathrm{b}^{* * *}}$ & $157.30 \pm 2.45^{\mathrm{b}^{* *}}$ & $41.22 \pm 2.16^{\mathrm{b}^{* * *}}$ & $34.24 \pm 1.40^{\mathrm{b**}}$ & $158.26 \pm 2.16^{\mathrm{b}^{* *}}$ \\
\hline $\mathrm{G}_{8}$ & $111.42 \pm 3.24^{\mathrm{b}^{* *}}$ & $149.22 \pm 2.40^{\mathrm{b**}}$ & $40.85 \pm 2.10^{\mathrm{b} * *}$ & $33.60 \pm 1.28^{\mathrm{b}^{* * *}}$ & $154.30 \pm 2.14^{\mathrm{b}^{* *}}$ \\
\hline $\mathrm{G}_{9}$ & $110.65 \pm 3.22^{\mathrm{b}^{* * *}}$ & $146.44 \pm 2.34^{\mathrm{b}^{* *}}$ & $39.60 \pm 2.05^{\mathrm{b}^{* *}}$ & $32.58 \pm 1.24^{\mathrm{b}^{* * *}}$ & $152.28 \pm 2.05^{b^{* *}}$ \\
\hline
\end{tabular}

\section{In vivo anti cancer activity of 6-SRGO and 6-SRGO-LLPS against Dalton's Ascitic Lymphoma (DAL) in mice}

The life span of the animal after starting the treatment for the cancer is the most reliable criteria to find out the efficacy of the drug used to treat the cancer (Clarkson et al., 1965). In this study, the average life span of tumor control group of animals was found to be $48 \%$ where as an increase in life span was observed up to $78 \%, 81 \%$ and $84 \%$ for group treated with $6-\mathrm{SRGO}$ at the doses of 100,200 , and $400 \mathrm{mg} / \mathrm{kg}$ body weight and $91.5 \%, 92.5 \%$ and $93.5 \%$ for group treated with 6-SRGO-LLPS at the doses of 100 , 200 and $400 \mathrm{mg} / \mathrm{kg}$ body weight respectively. However, in group treated with 5-FU the overall life span of the animals was found to be $94 \%$ which shows very potent cytotoxic in nature.

As shown in Table 3, except the WBC count, all other hematological parameters have been decreased significantly for groups treated with 6-SRGO-LLPS than the groups treated with 6-SRGO at all three doses, compared to normal control group of animals.

The induction of DLA cells, rises the level of cholesterol, aspartate amino transferase, alanine amino transferase and alkaline phosphatase to the significant level when compared to the normal group. The treatment with 6-SRGO-LLPS recovers the above mentioned changes to normal level than the group treated with 6-SRGO at all three doses (Table 3).

Packed cell volume as well as viable tumor cell count were reduced in group treated with 6-SRGO-LLPS more significantly than the groups treated with 6-SRGO at all three doses when compared to tumor control groups (Tables 4 and 5).

In DLA tumor, a rise in ascitic tumor volume was noticed. Ascitic fluid gives rise to a direct nutritional source for tumor cells and a sudden rise in ascitic fluid with tumor growth to meet the nutritional requirement of tumor cells (Prasad and Giri, 1994). Treatment with 6-SRGO-LLPS significantly reduces the increased level of ascetic fluid to the normal level when compare to the 6-SRGO at all three doses.

Usually, the major problem in the treatment of the cancer is the suppression of myeloma and the anemia (Price and Greenfield, 1958; Hogland, 1982). The anemia arises mainly because of reduction in the RBC count or reduction in the total hemoglobin count (Fenninger and Mider, 1954). Treatment with
6-SRGO and 6-SRGO-LLPS at all three doses brought backs all the hematological parameters to the normal level significantly.

Table 5: Effect of 6-SRGO and 6-SRGO-LLPS on the life span, body weight and cancer cell count of tumor induced mice.

\begin{tabular}{lcccc}
\hline Treatment & $\begin{array}{c}\text { Number of } \\
\text { animals }\end{array}$ & $\begin{array}{c}\text { \% ILS Life } \\
\text { span }\end{array}$ & $\begin{array}{c}\text { Increase in Body } \\
\text { weight grams }\end{array}$ & $\begin{array}{c}\text { Cancer cell } \\
\text { count ml } \times \mathbf{1 0}^{6}\end{array}$ \\
\hline $\mathrm{G}_{1}$ & 6 & $>30$ days & $2.22 \pm 0.68$ & - \\
$\mathrm{G}_{2}$ & 6 & $48 \%$ & $9.44 \pm 1.86^{\mathrm{a}^{* * *}}$ & $2.75 \pm 0.80^{\mathrm{a}^{* * *}}$ \\
$\mathrm{G}_{3}$ & 6 & $94 \%$ & $5.66 \pm 0.42^{\mathrm{b**}}$ & $1.30 \pm 0.22^{\mathrm{b}^{* * *}}$ \\
$\mathrm{G}_{4}$ & 6 & $78 \%$ & $5.98 \pm 0.84^{\mathrm{b**}}$ & $1.66 \pm 0.50^{\mathrm{b} * *}$ \\
$\mathrm{G}_{5}$ & 6 & $81 \%$ & $6.05 \pm 0.88^{\mathrm{b**}}$ & $1.38 \pm 0.23^{\mathrm{b}^{* * *}}$ \\
$\mathrm{G}_{6}$ & 6 & $84 \%$ & $6.18 \pm 0.94^{\mathrm{b**}}$ & $1.54 \pm 0.36^{\mathrm{b}^{* * *}}$ \\
$\mathrm{G}_{7}$ & 6 & $91.5 \%$ & $5.45 \pm 0.55^{\mathrm{b**}}$ & $1.34 \pm 0.18^{\mathrm{b}^{* * *}}$ \\
$\mathrm{G}_{8}$ & 6 & $92.5 \%$ & $5.22 \pm 0.32^{\mathrm{b**}}$ & $1.33 \pm 0.15^{\mathrm{b}^{* * *}}$ \\
$\mathrm{G}_{9}$ & 6 & $93.5 \%$ & $4.90 \pm 0.20^{\mathrm{b}^{* * *}}$ & $1.32 \pm 0.10^{\mathrm{b} * *}$ \\
\hline $\mathrm{G}_{1}$ & 6 & &
\end{tabular}

$\mathrm{G}_{1}$ - Normal Control, $\mathrm{G}_{2}$ - Cancer Control, $\mathrm{G}_{3}$ - Positive control, $\mathrm{G}_{4}$ to $\mathrm{G}_{6}$ - Treatment control (6-SRGO 100, 200, $400 \mathrm{mg} / \mathrm{kg}$ ), $\mathrm{G}_{7}$ to $\mathrm{G}_{9}$ - Treatment control (6-SRGO-LLPS 100, 200, $400 \mathrm{mg} / \mathrm{kg}$ ).

All values are expressed as mean \pm SEM for 6 animals in each group and results were analyzed by using One way ANNOVA, followed by Dunnettspost test.

${ }^{* *}$ Values are significantly different from normal control $\left(\mathrm{G}_{1}\right)$ at $\mathrm{P}<0.01$.

${ }^{* * b}$ Values are significantly different from cancer control $\left(\mathrm{G}_{2}\right)$ at $\mathrm{P}<0.01$.

Treatment with 6-SRGO-LLPS increased the life span of the mice, controlled the tumor volume and reduced the cell count of the tumor and normalized the hematological parameters more significantly than the group treated with 6-SRGO at all three doses. Thus the result shows that the 6-SRGO-LLPS exhibited better anticancer activity against DAL bearing mice as compare to the 6-SRGO at all three doses.

\section{CONCLUSION}

We have developed and investigated liposomes composed of lipids (DMPG-Na) and cholesterol as an effective nano carrier for the delivery of a natural lipophilic anticancer bioactive 6-SGL from 6-SRGO. The developed 6-SRGO-LLPS exhibited higher DC and sustained release of 6-SGL from 6-SRGO. Liposomal encapsulation of 6-SRGO resulted in remarkable stability for up to 90 days. Moreover, the 6-SRGO-LLPS demonstrated higher in 
vitro cytotoxic activity in human breast cancerMCF-7 cells and in vivo anticancer activity in DAL cells than 6-SRGO, which may bring about reduction in dose as well as cost. Thus 6-SRGOLLPS may be used to add value to new products by increasing anticancer activity, especially in functional foods directed to the breast cancer population, in which 6-SRGO play an important role on the attenuation of complications associated to cancer.

\section{ACKNOWLEDGMENTS}

The authors are thankful to the University Grant Commission-Basic Scientific Research (UGC-BSR) (File No.:F.41/2006 (BSR)/7-23/2007 (BSR) dated January 2013), Government of India, New Delhi, India for financial assistance to carry out the research work efficiently. The authors also sincerely acknowledge Tata Memorial Center, Advanced Centre for Treatment Research and Education in Cancer, Mumbai, India for the in vitro anticancer study.

\section{CONFLICT OF INTEREST}

The authors report no declarations of interest.

\section{REFERENCES}

Akbarzadeh A, Rezaei-Sadabady R, Davaran S, Woo SJ, Zarghami N, Hanifehpour Y, Samiei M, Kouhi M, Nejati-Koshki K. Liposome: classification, preparation, and applications. Nanoscale Res Lett, 2013; 8:102.

Bothiraja C, Kapare H, Pawar A, Shaikh K. Development of plumbagin-loaded phospholipid-Tween ${ }^{\circledR} 80$ mixed micelles: formulation, optimization, effect on breast cancer cells and human blood/serum compatibility testing. Ther Deliv, 2013; 4(10):1247-1259.

Brigger I, Dubernet C, Couvreur P. Nanoparticles in cancer therapy and diagnosis. Adv Drug Deliv Rev, 2002; 54(5):631-651.

Chen H, Lishuang L, Soroka D, Warin R, Parks T, Hu Y, Zhu Y, Chen X, Sang S. Metabolism of [6]-Shogaol in Mice and in Cancer Cells. Drug Metab Dispos, 2012; 40:742-753.

Clarkson B, Burchenal J. Preliminary screening of antineoplastic drugs. Prog Clin Cancer, 1965; 1:625-9.

Fenninger L, Mider G. Energy and nitrogen metabolism in cancer. Adv Cancer Res, 1954; 2:229-253.

Gao Z, Tian L, Hu J. Prevention of metastasis in a 4T1 murine breast cancer model by doxorubicin carried by folate conjugated $\mathrm{pH}$ sensitive polymeric micelles. J Control Release, 2011; 152(1):84-89.

Hogland H. Hematological complication of cancer chemotherapy, Seminars in Oncology, 1982; 9:95-102.

Jiang-nan Y, Yuan Z, Li W, Min P, Shan-shan T, Xia C, Hui Q, Xi-ming X. Enhancement of oral bioavailability of the poorly water-soluble drug silybin by sodium cholate/phospholipid-mixed micelles. Acta Pharmacologica Sinica, 2010; 31:759-764.

Kaushik P, Khokra SL, Rana AC, Kaushik D. Evaluation of anticancer activity of Pinus roxburghii Sarg. Against IMR-32 human neuroblastoma cancer cell line. Int J Pharm Clin Res, 2015; 7(1):105-108.

Kelly SB, Kevin MS, Aranee C, Luis A, Vondel R, Chen L, Bennett D, Emmanuel K, Andrea GB, Ian T, Zhimin X, Subramaniam S. Microencapsulation of ginger (Zingiber officinale) extract by spray drying technology. Food Sci Technol, 2016; 70:119-125.

Kim J, Lee S, Park H, Yang J, Shin T, Kim Y, Baek N, Kim S, Choi S, Kwon B, Leem K, Jung M, Kim D. Cytotoxic components from the dried rhizomes of Zingiber officinale Roscoe. Arch Pharm Res, 2008; 31(4):415-8.

Kumar P, Paul W, Sharma C. Green synthesis of gold nanoparticles with Zingiber officinale extract: Characterization and blood compatibility. Process Biochem, 2011; 46:2007-2013.

Laouini A, Jaafar-Maalej C, Limayem I, Sfar S, Charcosset C, Fessi H. Praparation, characterization and applications of liposomes: State of the art. J Colloid Sci Biotechnol, 2012; 1:147-168.

Li X, ZhangY, Fan Y. Preparation and evaluation of novel mixed micelles as nanocarriers for intravenous delivery of propofol. Nanoscale
Res Lett, 2011; 6(3):275.

Malam Y, Loizidou M, Seifalian A. Liposomes and nanoparticles: nanosized vehicles for drug delivery in cancer. Trends Pharmacol Sci, 2009; 30(11).

Mehta AK, Arora N, Gaur SN, Singh BP. Acute toxicity assessmentof choline by inhalation, intraperitoneal and oral routes in Balb/c mice. Regul Toxicol Pharmacol, 2009; 54:282-286.

Muthu M, Kulkarni S, Liu Y. Development of docetaxel-loaded vitamin E TPGS micelles: formulation optimization. effects on brain cancer cells and biodistribution in rats, Nanomed, 2012; 7(3):353-364.

Nikam A, Sathiyanarayanan L, Mahadik K. Mapping Pharmacokinetic and Tissue Distribution Profile of [6]-Shogaol from Ginger Oleoresin. Intl J Pharm Pharm Sci, 2013; 5(1):185-189.

Nikam A, Sathiyanarayanan L, Mahadik K. Validation of reversed-phase high-performance liquid chromatography method for simultaneous determination of 6-, 8-, and 10-shogaol from ginger preparations. Int J Pharm Pharm Sci, 2013; 5(1):432-437.

Oriania V, Alvimb I, Consolia L, Molinac C, Pastored G, Hubingera M. Solid lipid microparticles produced by spray chilling technique to deliver ginger oleoresin: Structure and compound retention. Food Res Int, 2016; 80:41-49.

Prasad S, Giri A. Anti tumor effect of cisplatin against murine ascites Dalton's lymphoma. Ind J Expetl Biology, 1994; 32:155-62.

Price V, Greenfield R. Anemia in cancer. Adv Cancer Res, 1958; 5:199-200.

Ratcharin N, Wongtrakul P, Indranupakorn R. Preparation of Zingiber officinale Extract Loaded Solid Lipid Nanoparticles. Biomat Appls, 2012; 506:389-392.

Sathiyanarayanan L, Arulmozi S, Chidhambarnathan N. Anti Carcinogenic activity of Leptadenia reticulataI against Dalton's ascitic lymphoma. Iran J Pharmacol Toxicol, 2006; 6:133-136.

Saxena V, Hussain M. Poloxamer 407/TPGS mixed micelles for delivery of gambogic acid to breast and multi drug resistant cancer. Int J Nanomed, 2012; 7(2):713-721.

Shukla Y, Singh M. Cancer preventive properties of ginger: A brief review. Food Chem Toxicol, 2007; 45:683-690.

Singh G, Kapoor, Singh P, Heluani C, Lampasona M, Catalan C. Chemistry, antioxidant and antimicrobial investigations on essential oil and oleoresins of Zingiber officinale. Food Chem Toxicol, 2008; 46:3295-3302.

Surh Y, Lee E, Lee J. Chemoprotective properties of some pungent ingredients present in red pepper and ginger. Mutat Res, 1998; 402:259-267.

Tong S, Xiang B, Dong D. Enhanced antitumor efficacy and decreased toxicity by self-associated docetaxel in phospholipid based micelles. Int J Pharmceut, 2012; 434(1):413-419.

Tulini F, Souza V, Echalar-Barrientos A, Thomazini M, Pallone E, Favaro-Trindade C. Development of solid lipid microparticles loaded with a proanthocyanidin rich cinnamon extract (Cinnamomum zeylanicum): Potential for increasing antioxidant content in functional foods for diabetic population. Food Res Int, 2016; 85:10-18.

Unnikrishnan M, Kuttan R. Tumor reducing and Anti-Carcinogenic activity of selected species. Cancer Lett, 1990; 51:85-89.

Uthumpa C, Indranupakorn R, Asasutjarit R. Development of Nanoemulsion Formulations of Ginger Extract. Adv Appl Mat Elect Eng II, 2013; 684:12-15.

Wu H, Hsieh M, Lo C, Liu C, Sang S, Ho C, Pan M. 6-Shogaol is more effective than 6-gingerol and curcumin in inhibiting 12-O-tetradecanoylphorbol 13-acetate-induced tumor promotion in mice. Mol Nutr Food Res, 2010; 54:1296-306.

How to cite this article:

Kemkar K, Sathiyanarayanan L, Sathiyanarayanan A, Mahadik K. 6-shogaol from ginger oleoresin loaded liposomes using DMPG-Na as a carrier enhances the in-vitro and in-vivo anticancer activity. J App Pharm Sci, 2018; 8(02): 001-010. 